\title{
A utilização do peptídeo botulínico no rejuvenescimento facial: relato de caso
}

\author{
The use of botulinum peptide in facial renewal: case report \\ El uso del péptido botulínico en el rejuvenecimiento facial: reporte de caso
}

Recebido: 08/09/2021 | Revisado: 15/09/2021 | Aceito: 17/09/2021 | Publicado: 19/09/2021

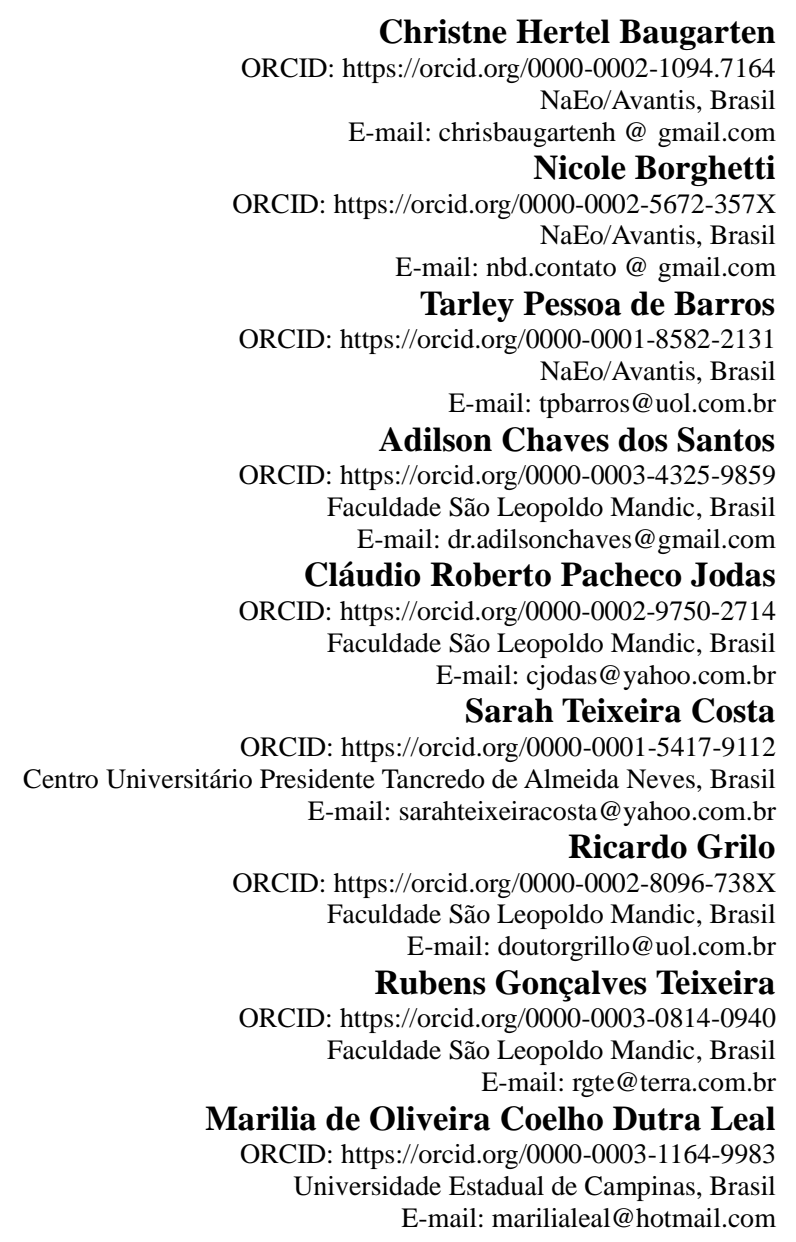

\section{Resumo}

A paciente, C.H.B, 33 anos, sexo feminino, compareceu à clínica da NAEO/SC, com queixa principal de: fissuras na pele, rugas, manchas senis com descoloração e irregularidades; em busca de tratamento para rejuvenescimento facial. Após anamnese e exame clínico optou-se pelo uso do microagulhamento em toda face seguida da aplicação do "Professional Dermoline" em esfregaço. Ao final fez-se a "Máscara Facial" por um período de 40 minutos. O mesmo protocolo foi repetido por mais duas vezes, totalizando três sessões da terapia, com intervalo de 30 dias entre elas. Foi realizada manutenção em casa com o "Sérum Antirrugas" durante todo o período de tratamento. A análise facial da pele foi realizada por meio do Scanner Facial FaceBox Pro® no qual a idade da pele da paciente foi de 31,23 anos. Na análise digital de pele realizada por meio do aparelho Skin Up ® a umidade foi de 22,3\% e a oleosidade de $33,4 \%$. Após o tratamento completo e novo exame, pelo FaceBox Pro® houve uma redução da idade de 31,46 para 30,17 anos e pelo Skin Up ® não foi necessária reavaliação, pois a pele da paciente já se encontrava próxima dos índices de normalidade. Pode-se concluir que quando o peptídeo botulínico é utilizado de forma adequada e com a indicação correta é possível obter resultados significativos na qualidade de pele do paciente.

Palavras-chave: Toxinas botulínicas Tipo A; Rejuvenescimento; Envelhecimento da pele.

\footnotetext{
Abstract

The patient, C.H.B, 33 years old, female, attended the NAEO/SC clinic with the main complaint of: skin cracks, wrinkles, age spots with discoloration and irregularities; looking for facial rejuvenation treatment. After anamnesis and clinical examination, it was decided to use microneedling all over the face, followed by the application of
} 
"Professional Dermoline" in a smear. At the end, the "Facial Mask" was made for a period of 40 minutes. The same protocol was repeated twice more, totaling three therapy sessions, with an interval of 30 days between them. Maintenance was carried out at home with the "Anti-wrinkle Serum" throughout the treatment period. Facial skin analysis was performed using the FaceBox Pro ${ }^{\circ}$ Facial Scanner in which the patient's skin age was 31.23 years. In the digital analysis of the skin performed using the Skin Up ${ }^{\circledR}$ device, the moisture content was $22.3 \%$ and the oil content was $33.4 \%$. After the complete treatment and a new examination, with FaceBox Pro® there was a reduction in age from 31.46 to 30.17 years and with Skin $U p \circledR$ it was not necessary to reassess, as the patient's skin was already close to normal indices. It can be concluded that when botulinum peptide is used properly and with the correct indication, it is possible to obtain significant results in the quality of the patient's skin.

Keywords: Botulinum toxins Type A; Rejuvenation; Aging of the skin.

\section{Resumen}

La paciente C.H.B, 33 años, mujer, acudió a la clínica NAEO / SC con el principal síntoma de: grietas en la piel, arrugas, manchas de la edad con decoloración e irregularidades; buscando tratamiento para el rejuvenecimiento facial. Después de la anamnesis y el examen clínico, se decidió utilizar microagujas en todo el rostro, seguido de la aplicación de "Professional Dermoline" en un frotis. Al final, se realizó la "Mascarilla Facial" por un período de 40 minutos. El mismo protocolo se repitió dos veces más, totalizando tres sesiones de terapia, con un intervalo de 30 días entre ellas. El mantenimiento se realizó en casa con el "Serum Antiarrugas" durante todo el período de tratamiento. El análisis de la piel facial se realizó con el escáner facial FaceBox Pro® en el que la edad de la piel del paciente fue de 31,23 años. En el análisis digital de la piel realizado con el dispositivo Skin Up®, el contenido de humedad fue del $22,3 \%$ y el contenido de aceite fue del 33,4\%. Tras el tratamiento completo y una nueva exploración, con FaceBox Pro® hubo una reducción de la edad de 31,46 a 30,17 años y con Skin Up® no fue necesario reevaluar, ya que la piel del paciente ya estaba cerca de los índices de normalidad. Se puede concluir que cuando el péptido botulínico se utiliza de forma adecuada y con la indicación correcta, es posible obtener resultados significativos en la calidad de la piel del paciente.

Palabras clave: Toxinas botulínicas tipo A; Rejuvenecimiento; Envejecimiento de la piel.

\section{Introdução}

A toxina botulínica foi descoberta em 1817 quando foi descrito pela primeira vez o botulismo, que causou mortes devido à intoxicação por veneno, pois interferia no sistema nervoso motor e autônomo, sendo proveniente de salsichas defumadas (Colhado, Boeing \& Ortega, 2009). Seus efeitos terapêuticos foram descobertos bem mais tarde, em 1919, mais especificamente dois tipos sorológicos do Bacillus botulinum (tipos Ae B) (De Paulo \& Oliveira, 2018). No entanto, somente no início da década de 1970, o sorotipo do tipo A foi utilizado pela medicina para corrigir o estrabismo.

Existem sete sorotipos diferentes de toxina (A, B, C1, D, E, F e G), sendo esta uma das toxinas bacterians mais potentes. A sua ação de paresia ocorre entre o terceiro e o décimo dia após a aplicação, com efeito supremo durante a $2^{\mathrm{a}}$ e a $3^{\mathrm{a}}$ semana, perpetuando esse efeito por um intervalo entre 6 semanas a 6 meses ou mais. O músculo esquelético permanece paralisado quimicamente até a ocorrência de brotamento de axônios que restabelecem a transmissão neuromuscular em conformidade com a resposta individual, condição clínica, dose e sorotipo da neurotoxina administrada (De Paulo \& Oliveira, 2018). A toxina botulínica é sintetizada como uma proteína de $150 \mathrm{kDa}$ que sofre modificação após a tradução em uma proteína de 100-kDa (cadeia pesada) e uma de 50kDa (cadeia leve) e são ligadas por uma ponte dissulfeto (Lacy et al., 1998).

A harmonização orofacial (HOF) consiste em um conjunto de procedimentos e técnicas com a finalidade de restabelecer a pele sob o aspecto funcional e estético. Preponderantemente atua na correção e/ou suavização de assimetrias faciais, harmonização de traços e linhas do rosto de acordo com a individualidade de cada paciente. A HOF conta com uma ampla gama de técnicas, sendo a toxina botulínica umas das mais utilizadas, pois a mesma pode ser empregada na prevenção ou suavização das marcas de expressão (De Paulo \& Oliveira, 2018), além de outros tratamentos estéticos como correção de assimetrias faciais devido a hemiparesias, situação encontradas em pacientes acometidos por acidentes vásculo-cerebrais e paralisia de Bell (Salles et al., 2021). O envelhecimento cutâneo é um processo degenerativo progressivo, resultante de um declínio fisiológico das funções do tecido cutâneo, tanto a nível epidérmico como dérmico (Addor, 2015). O envelhecimento cutâneo resulta da combinação de fatores intrínsecos e extrínsecos. Os intrínsecos podem ser traduzidos como envelhecimento 
cronológico, que resulta em afinamento da epiderme, aumento da fragilidade, e também diminuição da espessura dérmica e da vascularização, redução no número de fibroblastos e na sua capacidade metabólica, além de uma resposta menor a fatores de crescimento (Tadini, 2009).

A injeção subcutânea de toxina botulínica é uma forma de administração já popularizada no Brasil, porém existem outras formas de administração, como por exemplo a administração transdérmica (ou percutânea) do peptídeo botulínico (cadeia leve) no tratamento de fissuras na pele, rugas, manchas senis com descoloração e irregularidades da pele como no relato de caso descrito. Estas injeções de toxina botulínica podem ser realizadas somente com a toxina ou em conjunto com outras substâncias como o ácido hialurônico, com o intuitode hidratação e rejuvenescimento facial (Kim, 2021). Esta busca por uma pele de aparência mais jovem gerou muitas técnicas tópicas diferentes que compartilham o mesmo princípio de danificar a pele para causar fibrose, que causa então o enrijecimento da pele (Camirand \& Doucet, 1997). Historicamente, os peelings faciais foram os primeiros métodos de rejuvenescimento de pele. Esse dano, então, cria uma resposta inflamatória proporcional ao mesmo, o que resulta na deposição de colágeno (Fernandes, 2005).

O instrumento utilizado para a realização do microagulhamento é constituído por um rolo de polietileno encravado por agulhas de aço inoxidável e estéreis, alinhadas simetricamente em fileiras perfazendo um total de 190 unidades, em média, variando segundo o fabricante. $\mathrm{O}$ comprimento das agulhas se mantém ao longo de toda a estrutura do rolo e varia de $0,25 \mathrm{~mm}$ a 2,5mm de acordo com o modelo (Fabroccini \& Fardella, 2009). Apesar de Dr. Kenneth D. Steinsapir ter recebido a patente da técnica de microgotas de toxinas botulínica nos Estados Unidos da América, pois foi considerada única em 2006, na Ásia já era utilizada há alguns anos (Wu, 2016).

Atualmente é notório que os efeitos não neuronais da toxina botulínica na derme, como na redução da atividade das glândulas sebáceas e sudoríparas e no fibroblasto, na melhora na produção de fibras colágenas e na redução da expressão das metalanoproteases de matriz. Os efeitos dermoepidérmicos da toxina botulínica, ou de seus derivados, não substituem os efeitos neuromusculares, pelo contrário, agregam resposta ao tratamento dos sinais do envelhecimento facial (Schalka, 2021).

O Facebox Pro® é um sofisticado equipamento para a realização de fotografia digital padronizada da face com luz "natural" e luz ultravioleta. Ele tem um software que captura imagens do rosto do paciente de forma simultânea, por meio de luz RGB semelhante à luz do dia, e também da luz ultravioleta, do fotoenvelhecimento. O equipamento então é capaz de quantificar as rugas faciais, tamanho dos poros do paciente, manchas, entre outros. A partir daí o profissional da saúde estética tem acesso a relatórios, com gráficos e estudos comparativos como, por exemplo, antes/depois. É uma ferramenta contribui de maneira expressiva nos resultados, já que ele proporciona um estudo mais detalhado da pele do paciente (Doctor Systems, 2021).

O produto Dermoline Professional conta com uma nova tecnologia, que, ao invés de toxina botulínica injetável, utiliza-se somente da cadeia leve da toxinabotulínica, ligada ao nanocarreador denominado Nano-TPC (Nanotecnologia de Penetração Celular) (Schalka, 2021).

O Skin Analyser Digital®, da Skin Up, é um leitor de umidade, oleosidade e elasticidade da pele com tecnologia de análise de impedância bio-elétrica. Ele possui quatro funções: medição da umidade da pele (em percentuais); medição da oleosidade da pele (em percentuais); indicação da qualidade da elasticidade da pele (ícones sinalizam se a pele está BOA ou RUIM em relação à elasticidade) e; Indicação do equilíbrio da pele e a relação entre sua umidade e oleosidade (por meio das cores verde, amarela ou vermelha do visor). Quanto mais equilibrada, melhor será a aparência da pele (Medsam, 2021).

Diante do exposto, o objetivo do presente relato de caso é discutir sobre a eficácia do tratamento com a toxina botulínica associada ao microagulhamento no resjuvenescimento facial da pele por meio do uso de aparelhos que quantificam a idade, umidade e oleosidade da pele. 


\section{Metodologia}

O presente artigo trata de um estudo descritivo de caráter narrativo e reflexivo (Silva-Souza et al., 2021) e foi aprovado pelo comitê de ética em pesquisa da Faculdade São Leopoldo Mandic sob parecer n ${ }^{\circ}$ 4.910.256. O mesmo seguiu o protocolo CARE (Consensus-based Clinical Case Reporting) como guia para relatos de casos clínicos (Gagnier et al., 2013).

\section{Relato do caso clínico}

Paciente C.H.B, leucoderma, sexo feminino, 33 anos de idade, compareceu à Clínica Odontológica do Curso de Especialização em Harmonização Orofacial (HOF) do Núcleo Avançado de Estudos Odontológicos (NAEO) em Balneário Camboriú, Santa Catarina, em busca de rejuvenescimento facial com queixas de fissuras em pele, rugas, manchas senis com descoloração e irregularidades na pele (figuras 1, 2 e 3). A paciente foi esclarecida com relação às possibilidades de tratamento e aceitou a conduta proposta

Figura 1, 2 e 3: Fotos inicias da paciente em normas lateral direita, frontal e lateral esquerda.
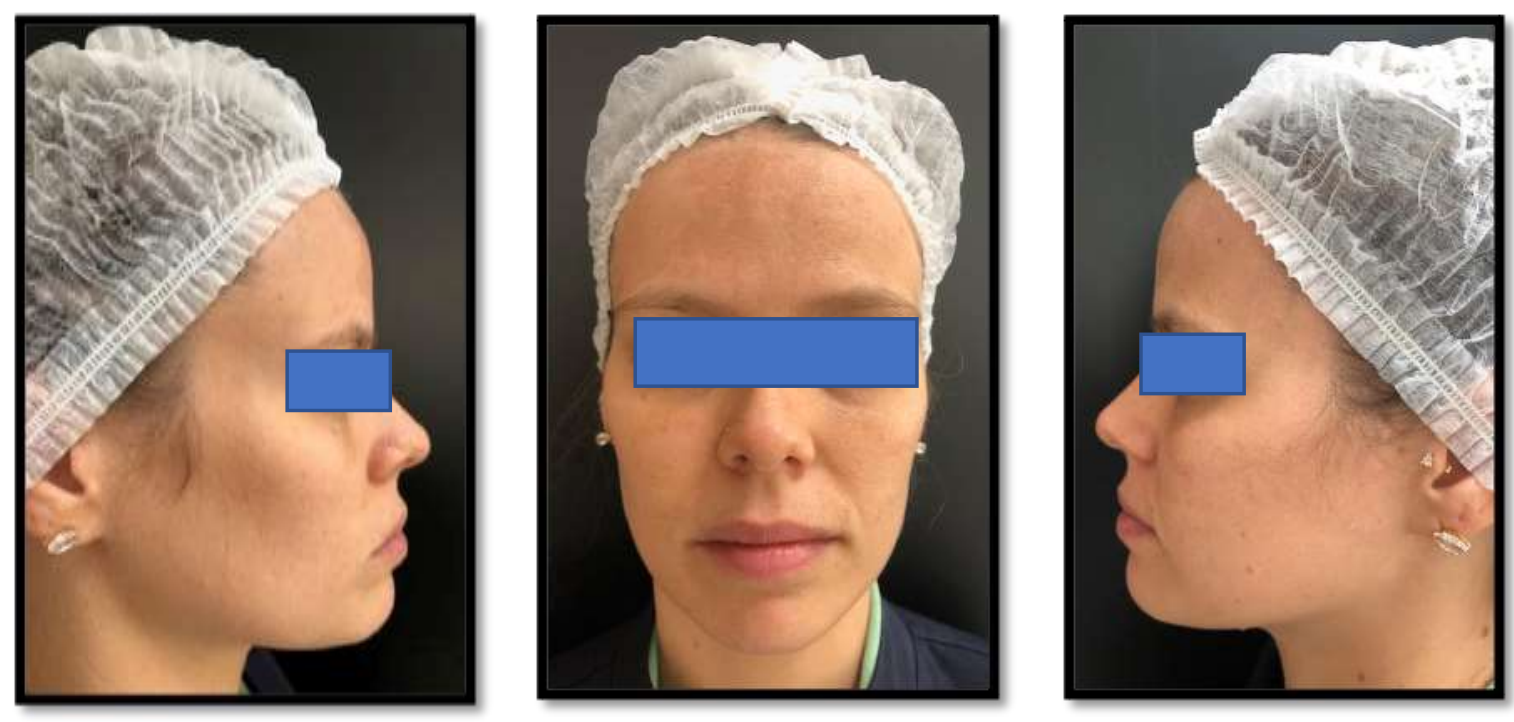

Fonte: Autores.

A análise facial foi registrada por meio de um protocolo fotográfico pré-estabelecido. Foi feita a análise facial da pele por meio do Scanner Facial FaceBox Pro® (Figura 4) e a análise digital da pele foi realizada por meio do aparelho Skin Up ${ }^{\circledR}$ (Figura 5). 
Figuras 4 e 5: Aparelhos Scanner Facial FaceBox Pro® e Skin Up®, respectivamente.
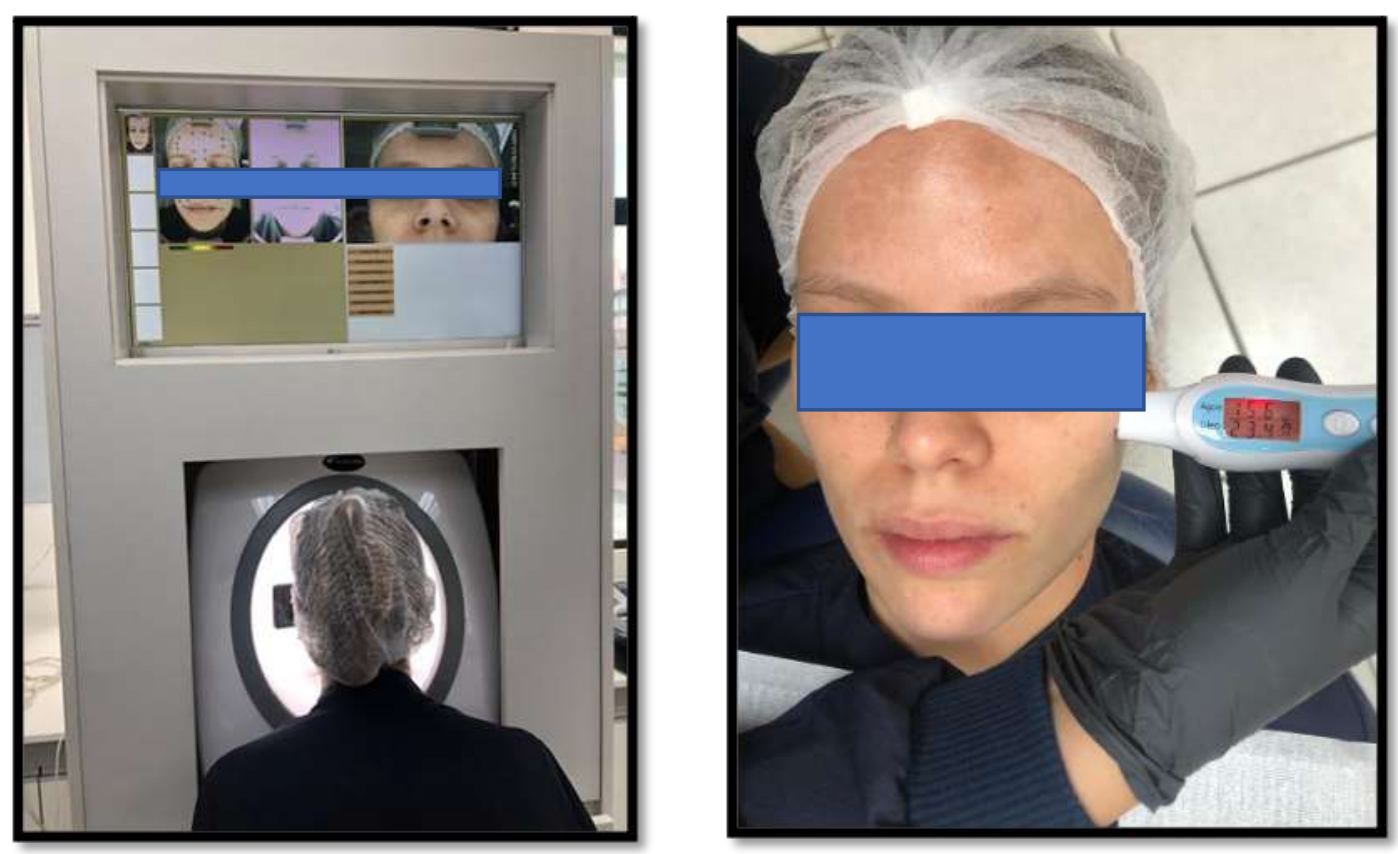

Fonte: Autores.

O aparelho Scanner Facial FaceBox Pro® avalia manchas, poros, irregularidades, rugas, oleosidade e desidratação na pele por meio de fotografia digital captada e indica a idade da pele da paciente de acordo com a imagem captada. No presente relato de caso a idade da pele da paciente é 31,46 anos antes do tratamento (Figura 6).

Figura 6: Idade da pele da paciente antes do tratamento (31,46 anos).

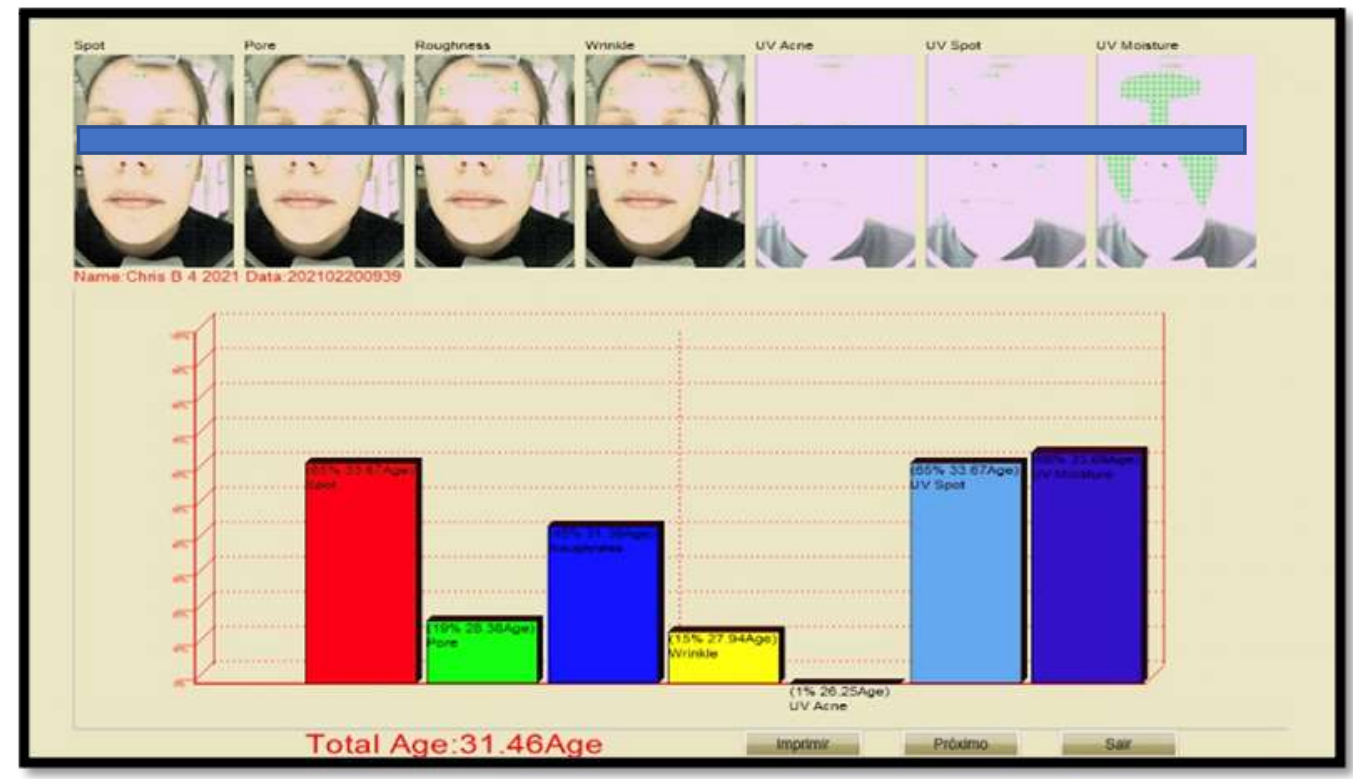

Fonte: Autores.

O aparelho Skin Up ®, analisador digital de pele, afere a oleosidade e a umidade da pele e apresenta valores ideais de umidade de 40 a $60 \%$ e de oleosidade de 15 a 35\%. No caso em tela a oleosidade foi de $23,4 \%$ e a umidade foi de $15,5 \%$ (Figura 7). 
Figura 7: Oleosidade $(23,4 \%)$ e umidade $(15,5 \%)$ da pele da paciente antes de iniciar o tratamento.

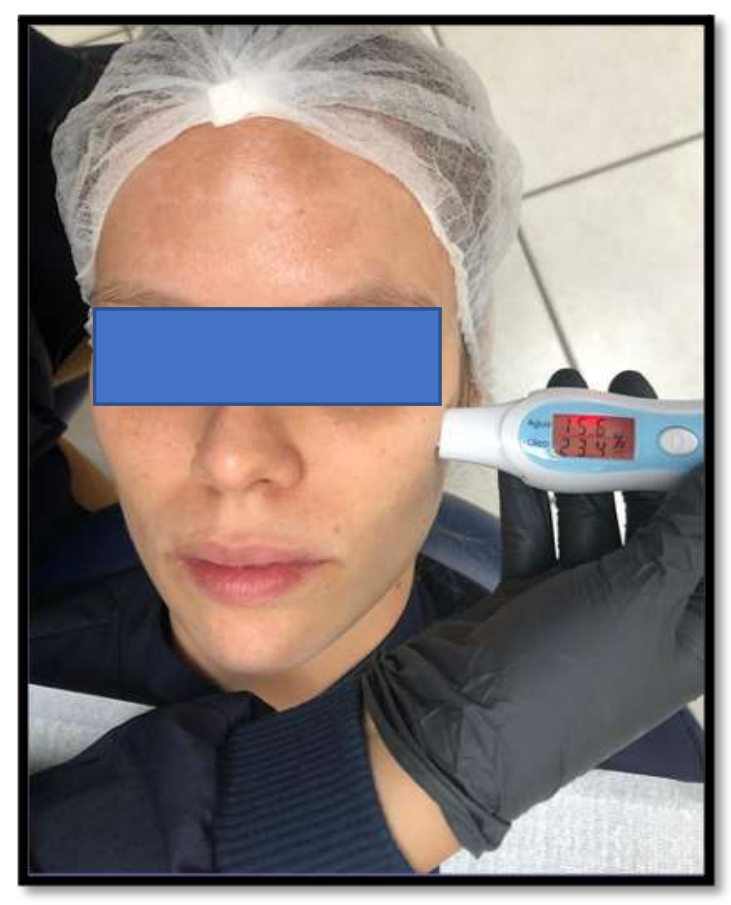

Fonte: Autores.

Após todas as avaliações, iniciou-se com a sessão de Microagulhamento em toda face com um dermarroler de $0,5 \mathrm{~mm}$. Após esse primeiro passo, limpou-se a pele com solução de cloreto de sódio 0,9\% (soro fisiológico) estéril, em seguida aplicou-se o Profissional Dermoline Meiskin Swiss ${ }^{\circledR}$ (ANVISA, 2012) em esfregaço em toda face já microagulhada. Por fim, fez-se o uso da máscara facial por um período de 40 minutos. O mesmo protocolo foi repetido por mais duas vezes, totalizando três sessões da terapia, com intervalo de 30 dias entre elas. $\mathrm{O}$ uso do sérum antirrugas foi preconizado como home care a ser utilizado duas vezes ao dia, a primeira aplicação no período da manhã, antes do protetor solar e a segunda à noite, após a higienização da pele.

\section{Resultados e Discussão}

Ao final dos 90 dias de ambos os tratamentos, os resultados finais foram: 1) no analisador digital, a umidade aumentou de $15,5 \%$ para $22,3 \%$ (valores ideais de umidade de 40 a $60 \%$ ) e a oleosidade aumentou de $23,4 \%$ para $33,4 \%$ (valores ideais de oleosidade de 15 a 35\%) (figura 8), 2), já no FaceBox Pro® a idade da pele reduziu de 31,46 para 30,17 anos (Figura 9). 
Figura 8. Resultado final para umidade $(22,3 \%)$ e oleosidade $(33,4 \%)$ da pele.

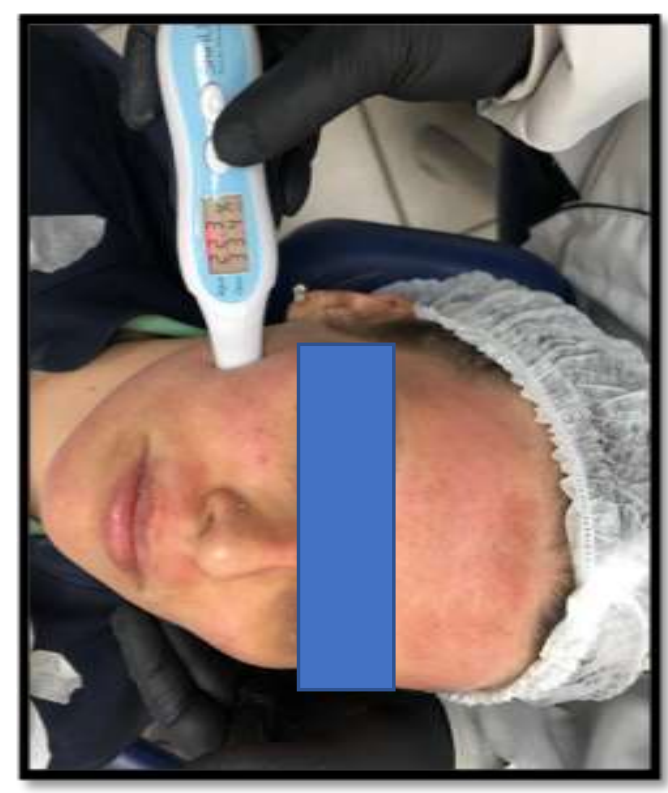

Fonte: Autores.

Figura 9: Resultado final para a idade da pele (30,17 anos).

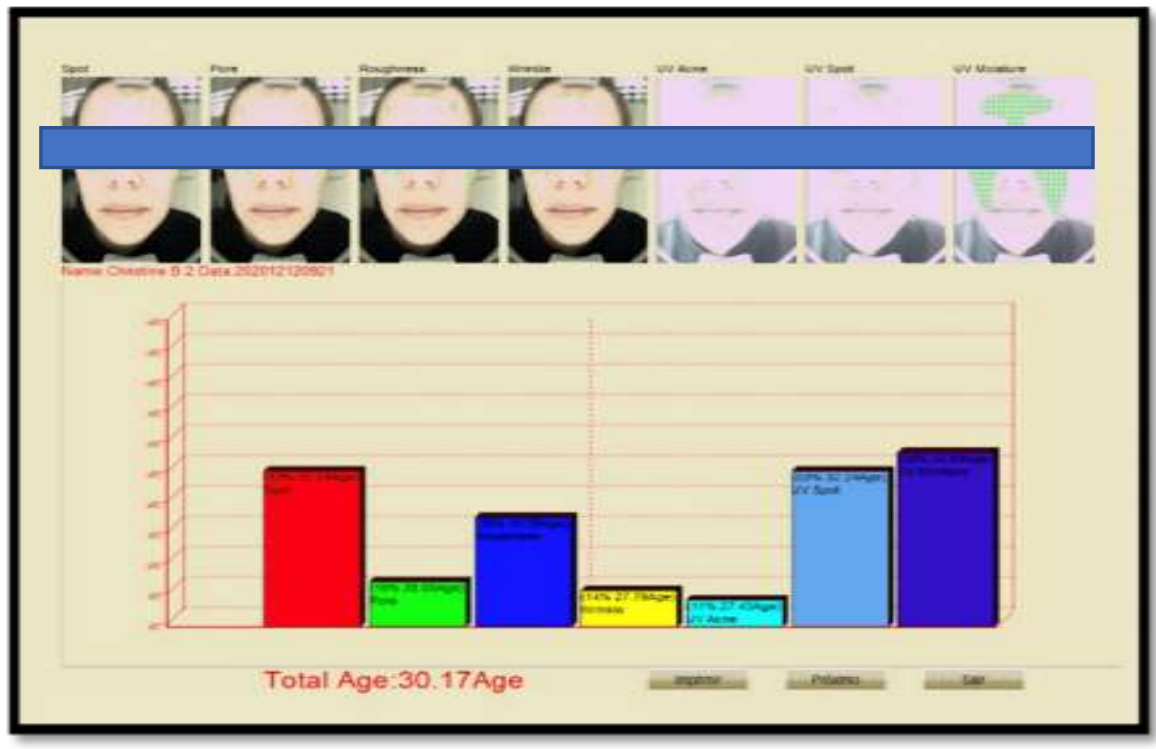

Fonte: Autores.

Estudo clínico (Kim, 2018) conduzido com 50 pacientes utilizou injeção intradérmica de ácido hialurônico estabilizado combinado com toxina botulínica A com auxílio de um injetor automático com múltiplas agulhas. A avaliação foi feita com auxílio de dermoscópio para alterações nas rugas finas e a hidratação dérmica foi medida pela perda de água transepidérmica e níveis de hidratação do estrato córneo. Chegou a resultados compatíveis com o presente relato de caso ao passo que as mudanças de perda de água transepidérmica e hidratação do estrato córneo foram estaticamente significativas em 4 e 8 semanas.

Estudo clínico italiano (Calvani et al., 2019) realata técnica de injeção dérmica de microdoses de toxina botulínica, não por seringa tradicional, mas com técnica de agulhamento que consiste em múltiplas microgotículas por dispositivo elétrico. A técnica é para tratamento de rosto e pescoço pela injeção da toxina botulínica na derme ou no plano subdérmico para 
melhorar a textura da pele e suavizar vincos horizontais. A solução de botox é hiperconcentrada quando comparada à diluição tradicional. A técnica foi aplicada a um grupo de 63 pacientes. E obteve resultados satisfatórios por melhorar o perfil mandibular, redução da flacidez da pele, atenuação das rugas dinâmicas causadas por hipertonia dos músculos mímicos, aumento do brilho e uma pele mais lisa sem causar a notória plastificação da aparência estética da pele. Assim como os resultados obtidos com o presente relato de caso.

A indução percutânea de colágeno (ICP) (Fernandes, 2005) é uma técnica simples e, com a ferramenta certa, pode perfurar completamente qualquer pele com facilidade e rapidez. Embora uma única sessão de tratamento possa não mostrar a mesma suavização/alisamento da pele visto com o laser. Uma segunda sessão de o tratamento pode ser feita. A técnica pode ser usada em áreas que não são adequadas para peeling ou uso de laser.

Estudo clínico retrospectivo (Bertossi et al., 2018) com quarenta e cinco pacientes de 35 a 52 anos foram submetidos a cinco sessões de laser Fraxel, uma sessão injeções de preenchimento dérmico com ácido hialurônico muito baixo G prime e injeção de Microbotox de janeiro de 2016 a 2017. Restou demonstrado que o uso de três tratamentos juntos, têm um resultado melhor, apesar de cada técnica isoladamente, para contrastar o envelhecimento facial e para melhorar a textura e qualidade da pele. O presente relato de caso utilizou apenas o peptídeo botulínico com o microagulhamento, ou seja, similar ao microbotox utilizado no estudo retrospectivo.

Estudo clínico com 25 de 30 pacientes tratados anteriormente com a Técnica de Nefertiti foram tratados com uma dose média de $154 \mathrm{U}$ da Técnica do microbotox. A contração das bandas platismais, a papada e volume do pescoço atingiram uma redução com significância estatística. A Técnica do microbotox melhorou a papada e o volume do pescoço mais do que a técnica de Nefertiti, enquanto a redução da contração das bandas platismais em repouso obtiveram melhor resultado com a Técnica de Nefertiti. A técnica de microbotoxina é um procedimento útil, simples e seguro para o rejuvenescimento da parte inferior do rosto e pescoço. É principalmente eficaz no tratamento do pescoço ptose de partes moles da face inferior, em contraste com a técnica de Nefertiti, que é mais eficaz nas bandas platismais (Awaida et al., 2019). Corroborando os resultados do nosso estudo clínico com relação à melhora da da qualidade da pele que resulta no rejuvenescimento facial.

Estudo experimental com o objetivo de estabelecer a correlação entre os comprimentos das agulhas do cilindro usadas para microagulhamento com a profundidade do dano infligido à pele. Foram realizadas biópsias nas áreas de pele de porcos vivos submetidos a microagulhamento com cilindros contendo 192 agulhas de $(0,5-1),(1,5-2)$ e $(2,5) \mathrm{mm}$. O exame microscópico realizado imediatamente após o procedimento revelou ectasia vascular com extravasamento de hemácias, afetando a derme papilar com agulhas de $0,5 \mathrm{~mm}$ e atingindo a derme reticular com agulhas mais longas. Os autores propõem classificar a lesão infligida como leve (agulhas de 0,5 mm), moderada (agulhas de 1,0 e 1,5 mm) e profunda (agulhas de 2,0 a 2,5 mm). O procedimento de microagulhamento pode ser indicado para um amplo espectro de alterações cutâneas quando o objetivo é estimular a produção de colágeno. Estabelecendo a relação entre o comprimento da agulha usada e o dano resultante à pele auxilia na escolha do microagulhamento ferramenta usada em diferentes direções. (Lima, 2013). No presente estudo foram utilizadas agulhas de $0,5 \mathrm{~mm}$, ou seja, formam estabelecidas lesões do tipo leve na pele.

\section{Conclusão}

Pode-se concluir que quando o peptídeo botulínico é utilizado de forma adequada e com a indicação correta é possível obter resultados significativos na qualidade de pele do paciente. Trata-se de um tratamento seguro, comprovadamente eficiente e de baixo custo.

São necessários mais estudos, como ensaios clínicos randomizados, acerca da eficácia do tratamento com a toxina botulínica associada ao microagulhamento no resjuvenescimento facial da pele por meio do uso de aparelhos específicos que quantificam a idade, umidade e oleosidade da pele. 


\section{Referências}

Addor, F. A. S. (2015) Influência de um suplemento nutricional com peptídeos de colágeno nas propriedades da derme. <http://www.surgicalcosmetic.org.br/detalhe-artigo/400/Influencia-de-um-suplemento-nutricionalcompeptideos-de-colageno-nas-propriedades-da-derme>.

ANVISA. (2012). Guia para Avaliação de Segurança de Produtos Cosméticos. Agência Nacional de Vigilância Sanitária (ANVISA). Brasília. http://portal.anvisa.gov.br/documents/106351/107910/Guia+para+Avalia\%C3\%A7\%C3\%A3o+de+Seguran\%C3\%A7a+de+Produtos+Cosm\%C3\%A 9ticos/ab0c660d-3a8c-4698-853a-096501c1dc7c

Awaida, C. J., Jabbour, S. F., Rayess, Y. A., El Khoury, J. S., Kechichian, E. G. \& Nasr, M. W. (2018). Evaluation of the Microbotox Technique: An Algorithmic Approach for Lower Face and Neck Rejuvenation and a Crossover Clinical Trial. Plast Reconstr Surg. 142(3), 640-649.

Bertossi, D., Giampaoli, G., Lucchese, A., Manuelli, M., Albanese, M., Nocini, R. \& Nocini, P. F. (2019). The skin rejuvenation associated treatment-Fraxel laser, Microbotox, and low G prime hyaluronic acid: preliminary results. Lasers in Medical Science. 10.1007/s10103-019-02738-z

Calvani, F., Santini, S., Bartoletti, E., \& Alhadeff, A. (2018). Personal Technique of Microinfiltration with Botulin Toxin: The SINB Technique (Superficial Injection Needling Botulinum). Plastic Surgery, 229255031880033. 10.1177/2292550318800330

Camirand, A. \& Doucet, J. (1997) Needle dermabrasion. Aesthetic Plast Surg. 21(1), 48-51

Colhado, O. C. G., Boeing, M. \& Ortega, L. B. (2009). Botulinum Toxin in Pain Treatment. Rev Bras Anestesiol. 59(3), 366-81.

De Paulo, E. V. \& Oliveira, R. C. G. (2018) Avaliação e sugestão de protocolo estético para aplicação de toxina botulínica do tipo A em pacientes adultos. Revista Uningá., 55(4), 158-167.

Fabroccini G \& Fardella N. (2009). Acne scar treatment using skin needling. Clin Exp Dermatol. 34(8):874-9.

Fernandes, D. (2005). Minimally Invasive Percutaneous Collagen Induction. Oral and Maxillofacial Surgery Clinics of North America. 17(1), 51-63. 10.1016/j.coms.2004.09.004

Gagnier, J.J., Kienle, G., Altman, D.G., Moher, D., Sox, H. \& Riley, D.; Care Group. (2013). The CARE guidelines: consensus-based clinical case reporting guideline development. BMJ Case Rep. 23. 10.1136/bcr-2013-201554.

Kim, J. (2018). Clinical Effects on Skin Texture and Hydration of the Face Using Microbotox and Microhyaluronicacid. Plastic and Reconstructive Surgery Global Open, 6(11), e1935. 10.1097/gox.0000000000001935

Kim, JS. (2021). Fine Wrinkle Treatment and Hydration on the Facial Dermis Using HydroToxin Mixture of MicroBotox and MicroHyaluronic Acid. Aesthet Surg J. 18;41(6):NP538-NP549. 10.1093/asj/sjaa231.

Lacy, D. B., Tepp, W. \& Cohen, A. C. et al .(1998). Crystal structure of botulinum neurotoxin type A and implications for toxicity. Nat Struct Biol. 5(10):898902

Lima, E. V. A., Lima, M. A. \& Takano, D. (2013). Microneedling experimental study and classification of the resulting injury. Surg Cosmet Dermatol. $5(2): 1104$.

Salles, A. G., Mota, W. M., Remigio, A. F. D. N., De Andrade, A. C. H. \& Gemperli, R. (2021). Management of Post-Facelift Facial Paralysis with Botulinum Toxin Type A. Aesthet Surg J. 10.1093/asj/sjab311.

Schalka, S. (2021). Associação de microagulhamento ao peptídeo botulínico em nanoestrutura no tratamento do envelhecimento facial. www.dermatologia.meiskin.com.br].

Silva-Souza, L. G., De Oliveira, L. D., Nunes, G. P., dos Santos Cividanes, L., Dahan, C. M., Pereira, A. K. G. \& E Silva, L. F. D. C. (2021). Effectiveness of the low-level laser therapy in the management of bisphosphonate-induced osteonecrosis of the jaws: A case report. Research, Society and Development, 10(6), e17510615199-e17510615199.

Tadini, K. A. (2009). Development and clinical evaluation of the effects of dermocosmetic formulations containing dimethylaminoetanol or acetyl hexapeptide-3. <http://www.teses.usp.br/teses/disponiveis/60/60137/tde-30092009-185011/en.php>.

Wu, W. T. L. (2016). Reply. Plastic and Reconstructive Surgery, 138(6), 1073e-1074e. 10.1097/prs.0000000000002820 